\title{
Species turnover in plants does not predict turnover in flower-visiting insects
}

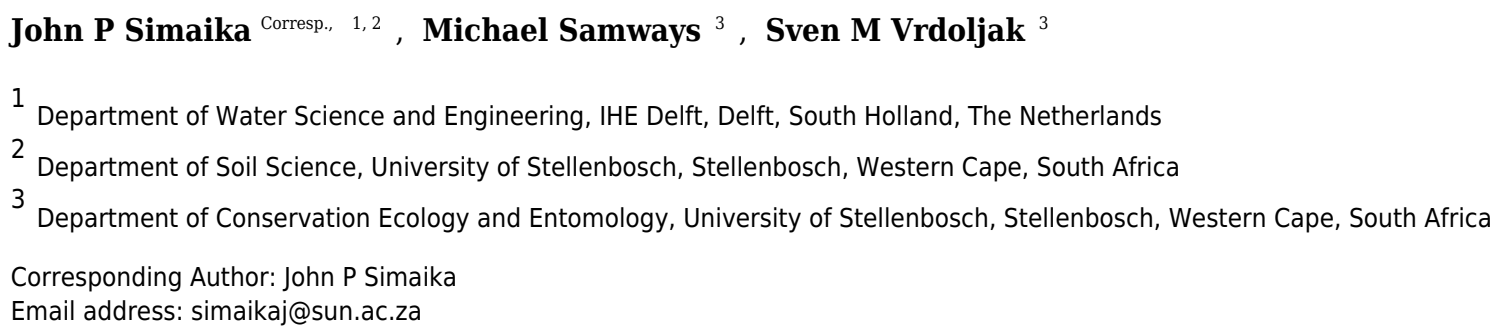

Congruence between plant and insect diversity is considered possibly useful in conservation planning, as the better known plants could be surrogates for the lesser known insects. There has been little quantification of congruence across space, especially in biodiversity rich areas. We compare here species richness, and turnover relationships between plants and flower-visiting insects across space $(0.5-80 \mathrm{~km})$ in natural areas of a biodiversity hotspot, the Cape Floristic Region, South Africa. A total of 22352 anthophile individuals in 198 species and 348 plant species were sampled. A comparison between the plants and anthophiles suggest significant concordance between the two assemblages. However, turnover was weaker in plants than in anthophiles. Plant turnover decreased with greater geographical distance between plot pairs. In contrast, insect turnover remained high with increasing geographical distance between plot pairs. These findings suggest that while patterns of plant diversity and distribution shape flower-visiting insect assemblages, they are not reliable surrogates. The conservation significance of these results is that specialist mutualisms are at greatest risk, and that set-asides on farms would help improve the functional connectivity leading to the maintenance of the full range of mutualisms. 


\section{Species turnover in plants does not predict turnover in} 2 flower-visiting insects

3

4 John P. Simaika ${ }^{1,2}$, Michael J. Samways ${ }^{3}$, Sven M. Vrdoljak ${ }^{3}$

$5{ }^{1}$ Department of Water Science and Engineering, IHE Delft, 2611 AX, The Netherlands

$6 \quad 2$ Department of Soil Science, Stellenbosch University, Private Bag X1, Matieland, 7602, South

7 Africa

$8{ }^{3}$ Department of Conservation Ecology and Entomology, Stellenbosch University, Private Bag 9 X1, Matieland, 7602, South Africa

10 John Simaika (simaikaj@sun.ac.za) (author for correspondence)

11

12 ABSTRACT

13 Congruence between plant and insect diversity is considered possibly useful in conservation

14 planning, as the better known plants could be surrogates for the lesser known insects. There has been little quantification of congruence across space, especially in biodiversity rich areas. We compare here species richness, and turnover relationships between plants and flower-visiting insects across space $(0.5-80 \mathrm{~km})$ in natural areas of a biodiversity hotspot, the Cape Floristic Region, South Africa. A total of 22352 anthophile individuals in 198 species and 348 plant species were sampled. A comparison between the plants and anthophiles suggest significant concordance between the two assemblages. However, turnover was weaker in plants than in anthophiles. Plant turnover decreased with greater geographical distance between plot pairs. In contrast, insect turnover remained high with increasing geographical distance between plot pairs. These findings suggest that while patterns of plant diversity and distribution shape flowervisiting insect assemblages, they are not reliable surrogates. The conservation significance of these results is that specialist mutualisms are at greatest risk, and that set-asides on farms would help improve the functional connectivity leading to the maintenance of the full range of mutualisms. 


\section{Introduction}

30 Current extinction rates are of great concern (Pimm et al., 2014), with the achieving of

31 conservation goals requiring an understanding of threats, the location of these threats, and

32 determining how to avert them (Joppa et al., 2016). Yet to make informed conservation

33 decisions, it is rarely possible to measure and account for all components of biodiversity, and so

34 conservation planning is often based on surrogates, under the assumption that unknown diversity

35 should also be effectively conserved by strategies for more familiar taxa or habitats (Rodrigues

36 \& Brooks, 2007; Wiens et al., 2008; Grantham et al., 2010). Effective surrogacy relies strongly

37 on the degree of congruence between the surrogate or indicator taxa and target groups.

Congruence between plant and insect diversity has been widely discussed, with varying

results depending on region, taxa, and diversity measures used. Although plant diversity can

predict herbivorous insect diversity (Novotny et al., 2006), the relationship may not necessarily

hold for non-herbivorous insects (Fontúrbel et al., 2015). Furthermore, tests of taxonomic surrogacy often produce contradictory results (Kremen, 1992; Prendergast, 1997; Duelli \& Obrist, 1998; van Jaarsveld et al., 1998;Osborn et al., 1999; Dauber et al., 2003).

Assessing the value of congruency for identifying surrogates is challenging (Lovell et al. 2007), as spatial scale (Favreau et al., 2006) and the history of focal groups such as plants and insects (Ponel et al., 2003), play important roles. While there may be congruence between focal groups at very large spatial scales (Lamoreux et al., 2006; McKnight et al., 2007), this may not be the case at the smaller scale of conservation planning at the local level (Ricketts et al., 2002; Stork \& Habel 2014). Furthermore, for surrogacy to be effective, the focal groups must respond to environmental variables in a similar way and must be equally sensitive (Pharo et al., 1999), and for conservation planning this includes responses to human impacts (Kirkman et al., 2012). In addition, there is the obvious factor that insects overall are more mobile than plants and can more respond quickly to environmental change, which has happened both in the deep (Ponel et al., 2003) and recent past (Hickling et al., 2006).

Flower-visiting insects are highly mobile and show a wide range of specificity to the plant species they visit, with interactions between plants and insects ranging along a continuum from highly specialised to generalised (Pauw, 2013). The needs of anthophiles are not only restricted to plants, and also include aspects such as resting, courtship and mating, ovipositioning 
59 or nesting, and avoiding death (Vanbergen et al., 2013; Goulson, 2015; Gill et al., 2016). This

60 means that anthophiles are sensitive to a range of factors that may not affect plants.

The Cape Floristic Region (CFR) biodiversity hotspot has one of the highest levels of

62 plant species richness and endemism in the world, with $69 \%$ of 9000 recorded plants endemic to

63 the area (Goldblatt \& Manning, 2002). There is still disagreement on whether insect diversity

64

65

66 matches the high levels of plant species richness in the CFR. Giliomee (2003), after conducting a study on herbivorous insects in the CFR, suggested that the CFR is not proportionately rich in herbivorous insect species, the exception being a guild of endophagous insects. Giliomee (2003) attributed this to the sclerophyllous nature and chemical defences of the plants, considering them a poor source of food for insects. On the other hand, Wright \& Samways (2000), in their study on endophagous insects on Proteaceae in South Africa, found proportionately high species richness of herbivorous insects in the CFR. Similarly, Kemp and Ellis (2017) found similar numbers of herbivorous insects per Restionaceae plant species, but as the plant species is so high in the region, the number of herbivorous insect species is inevitably high. Furthermore, Procheş \& Cowling (2006), comparing the diversity patterns of plant-inhabiting insects in the local fynbos vegetation to that of three neighbouring biomes, found that fynbos insects are diverse, and follow the generally established plant-insect herbivore diversity relationship, as suggested also by Hawkings \& Porter (2003).

Conservation planning and priorities are well established in the CFR, with much focus on spatial planning and goal-setting for conservation strategies (Cowling et al., 2003; Pressey et al., 2003). The basis of this work rests largely on Broad Habitat Units (BHUs) (Cowling \& Heijnis, 2001), which are defined using climate, topography, geology and vegetation, as well as some ecological processes. These methods are still limited to taxa such as plants for which the necessary, detailed distribution data are available. Yet we know comparatively little about the diversity and distribution of insects in any biodiversity hotspot, including the CFR, nor how well they would be protected within these spatial planning frameworks.

It is essential for effective conservation planning to consider congruency across taxa, as the choice of organisms have a strong influence over the representativeness of protected area networks. Maximizing the representativeness of taxa is done by considering their changes of beta diversity in the landscape (Socolar et al 2016). The beta diversity measure consists of two components, the nestedness and turnover of species communities (Baselga, 2010). Turnover 
90 across a landscape occurs when species are replaced, creating distinct assemblages by the

91 addition of novel species. Taxa that exhibit high spatial turnover require patches of high quality

92 habitat to help conserve their communities (Baselga, 2010).

93 Here, we compare species turnover of plant assemblages and closely associated

94 assemblages of flower-visiting insects (anthophiles) in natural and semi-transformed habitats in

95 the CFR, across space from $0.5 \mathrm{~km}$ to $80 \mathrm{~km}$. We pose two key questions: 1) Are the species

96 richness and turnover of anthophiles comparable across space to that of plants in the CFR?, and,

97 2) Is the community composition of anthophiles in a distance group related to local plant

98 community composition? This study therefore addresses two issues that have been previously

99 overlooked: the interrelationship between two mutually dependent groups, and how this

100 relationship is affected by geographic distance. This knowledge is instrumental for informing

101 conservation planning in the region and elsewhere in terms of plants and pollinators.

102

103 Methods

104

105

Study sites

106 Permissions for conducting the study were obtained from the relevant authority at: Helderberg

107 Municipal Nature Reserve and Hottentots Holland Provincial Nature Reserve - permission from

108 Cape Nature (Permit No. 372/2003); Cordoba Wine Estate, Vergelegen Wine Estate, Diepklowe

109 Private Nature Reserve, Elandsberg Private Nature Reserve - permission from manager/owner.

110

111 This study was conducted in the lowlands of the CFR, which includes threatened habitats

112 (Rouget et al., 2003). Six sites across part of the region, either in formally protected areas, or on

113 farms where land had been set aside for conservation purposes, were selected (Figure 1, Table 1).

114 At each of these sites, between one and four area plots were selected, all below $400 \mathrm{~m}$ a.s.1., and

115 which represented the heterogeneity of natural lowland habitats in the region. In total, 16 plots

116 were used in analyses.

117

\section{Insect sampling}

119 Sampling took place over a three-month period (September-November 2005) to coincide with 120 the time of peak flowering at each of the 16 plots. Vegetation and flowering status were 
121 measured a day before transect sampling (see the next section on Vegetation transects for further 122 details).

123 Insects were surveyed using coloured pan traps (Vrdoljak and Samways, 2012).

124 Anthophiles in the CFR (Picker \& Midgley, 1996) and elsewhere (Campbell \& Hanula, 2007;

125 Saunders \& Luck, 2013) show differential colour preferences to pan traps, so a range of colours

126 were used: red, orange, yellow, blue, violet, and white. Polypropylene tubs (RL350, Marco

127 Plastics, Alberton South Africa), $115 \mathrm{~mm}$ diameter by $50 \mathrm{~mm}$ deep (350 $\mathrm{ml}$ volume), were

128 painted with gloss enamel paint (Dulux SA, Alberton, South Africa). For each site, three arrays

129 of six coloured pan traps were used, arranged in a cross-shaped configuration of three $50 \mathrm{~m}$ lines

130 at each of the 16 plots, with the six colours arranged randomly at $10 \mathrm{~m}$ intervals on each line

131 (Figure 1).

132 Pans were elevated and set at the level of flowers in the surrounding vegetation, and half

133 filled with water, with a little detergent added to reduce surface tension. Elevating pan traps to

134 the level of the canopy where insects are actively foraging significantly increases catches (Tuell

$135 \&$ Isaacs, 2009). Trapping was only on sunny days, from $08 \mathrm{~h} 00$ to $17 \mathrm{~h} 00$. Trapped insects were

136 removed from the water and preserved in $80 \%$ ethanol for later identification. Initial

137 identifications were to morphospecies (Oliver \& Beattie, 1996), with scientific identification to

138 species where possible using the entomology collection in the Iziko South African Museum,

139 Cape Town. Here, we refer to both morphospecies and species as 'species'. Appendix S2 lists all 140 insect species identified in this study.

\section{Vegetation transects}

143 At each of the 16 plots, vegetation was surveyed the day before the first day of pan trapping.

144 Vegetation composition, height and cover were measured over three, $50 \mathrm{~m}$ transects per plot.

145 These vegetation transects were along the same line transects as the three pan trap lines at each

146 plot. All plants that covered the transect line were measured (height in $\mathrm{cm}$, length of transect in $147 \mathrm{~m}$ ), identified to species level, and their flowering status recorded (not flowering, flowering, in

148 bud, in seed). Open patches of ground were recorded and classified according to whether they

149 were bare ground, rock, leaf litter or woody debris. 


\section{Statistical analyses}

153

154 Species richness estimates

155 For insects, total abundance of each species per plot was calculated from the pooled data of six 156 arrays per plot (three arrays $\mathrm{x}$ two sample days per plot). For plants, data from all three transects

157 were pooled for each plot. This was done so as to calculate the total intercept distance covered by

158 each plant species and ground cover category (i.e. the effective abundance in terms of area

159 covered by each species or category) at each plot. Species richness was estimated using the

160 EstimateS Version 8.0 software package (Colwell, 2009; Colwell et al. 2012), using the pan trap

161 data (three arrays $\mathrm{x}$ two sample days per plot). Many different species richness estimators are

162 available, each with their own combinations of precision and bias that affect their accuracy

163 (Walther \& Moore, 2005). Given that certain anthophiles were highly abundant in pan trap

164 samples, an incidence-based estimator, the Incidence Coverage Estimator, ICE (Chao et al.,

165 2000), was calculated for each plot, using 1000 randomisations, with replacement. The same

166 procedure for calculating the ICE was followed for the pooled (three transects) vegetation data

167 for each plot.

168

169 Species diversity

170 The Shannon diversity index was calculated for both plant and insect data in PRIMER Version 6

171 (Primer-E Ltd 2002, Clarke \& Warwick, 2001). A covariance analysis was conducted to test the

172 significance of the relationship between insect and plant diversity.

173

174 Pan and plot assemblage similarity

175 Plots were classified using the CLUSTER routine in PRIMER Version 6 (Primer-E Ltd 2002,

176 Clarke \& Warwick, 2001). Cluster analysis was based on Bray-Curtis similarities of the square-

177 root transformed vegetation and pan trap data for each plot, which grouped them according to

178 similarity of their plant and anthophile assemblages respectively. Plots were classed using a

179 Similarity Profile (SIMPROF) analysis on the null hypothesis that a specific sub-cluster could be

180 recreated by permuting the entry sites. Significant branches (SIMPROF, $p<0.05)$ were then

181 used to class plots together. The results of the analyses are presented in Appendix S3.

182 


\section{Species turnover}

184 Seriation is used to test for species turnover along a spatial gradient (Brower and Kyle 1988;

185 Clarke et al. 1993), and thus is an effective tool for detecting trends in taxon turnover that may

186 be present (Clarke and Warwick, 2001). The index of seriation is given by Rho (q), ranging from

$187-1$ to +1 , and provides a p-value at the $5 \%$ significance level. Values closer to -1 or to +1 indicate

188 low community similarity, while values close to zero indicate high community similarity. The

189 RELATE function in PRIMER V6 was used to analyse the non-random spatial serial correlation

190 of each set of assemblage data (plants and insects) between all the elements of Sorensen

191 similarity matrices. The Sorensen similarity matrices were calculated from Bray-Curtis similarity

192 matrices calculated from presence-absence transformed species abundance data. The RELATE

193 function was then used to calculate the Spearman rank correlation coefficient between the plant

194 and insect assemblage datasets. The Spearman's rank coefficient can range from 0 to 1 , where 1

195 is a perfect match between sample relationships.

197 To test for spatial relationships and species turnover, Sorensen pair-wise dissimilarity of insect

198 and plant species was calculated in the package betapart (version 1.5.0; Baselga and Orme 2012)

199 using R (version 3.4.3). Non-linear regressions were then fitted to the plant or insect datasets. To

200 obtain $\mathrm{r}$ - and p-values, data were linearized using $\log 10$.

201

202 Effect of plant species composition on insect composition

203 In order to test whether plant species composition has a significant effect on anthophile species

204 composition, we used an Redundancy Analysis (RDA) approach developed by Kemp et al.

205 (2017) in R (version 3.4.3), using the package vegan (version 2.4-6; Oksanen et al. 2018).

206 Forward selection in RDA was used to assess the influence of Hellinger-transformed plant

207 species abundance on insect composition. Only the plant species selected by the forward

208 selection were retained. Redundancy analysis was then performed on Hellinger-transformed

209 insect species abundances, with eight plant species as constraining variables and geographical

210 distance as the conditioning variable. Geographical distance was converted to a rectangular

211 Principal Coordinate of Neighbour Matrix (PCNM) for this analysis. To test the significance of

212 variables, a permutational ANOVA test was done on the RDA. 
214 Vegetation structure and composition

215 To compare the effects of vegetation structure and composition of the plant assemblage on

216 flower-visiting insect assemblages at each plot, a number of variables were compiled from the

217 vegetation data (Table 2). Plant species composition at each plot was summarised using

218 detrended correspondence analysis (DCA) in CANOCO Version 4.53 (ter Braak \& Šmilauer,

219 2004) as the detrended segment lengths reported by CANOCO (maximum segment length $>4$ )

220 indicated that the data were unimodally distributed (Lepš \& Šmilauer, 2003). Scores from the

221 first DCA axis, which accounted for $11.5 \%$ of total variation in the dataset were used as a

222 measure of similarity between sites (Total inertia $=5.251$, cumulative $\%$ variance described by 4

223 axes $=24.7)$.

224 The effects of vegetation structure and composition were tested in CANOCO using a

225 canonical redundancy analysis (RDA) of anthophile assemblage data. Unlike the plant data, the

226 segment lengths of an initial DCA indicated a linear distribution, more suited to an RDA (Lepš

$227 \&$ Šmilauer, 2003). The ordination was initially constrained by the nine vegetation variables.

228 Stepwise selection was then used to select a subset of the four best fitting variables for the final

229 model, based on partial Monte-Carlo permutation tests to assess the usefulness of each potential

230 variable (Lepš \& Šmilauer, 2003). Variance partitioning (Borcard et al., 1992) was used to

231 calculate the relative contributions of the final four variables following procedures in CANOCO

232 described by Lepš and Šmilauer (2003).

233

\section{Results}

235 A total of 22352 anthophile individuals were sampled, falling into 198 species. For plants, a

236 total of 348 species were recorded.

237

238

\section{Species richness estimates}

239 Observed and estimated plant species richness varied widely between plots (Table 3). Analysis

240 of variance analysis did not detect any difference in estimated plant species richness between

241 plots $(\mathrm{F}$-value $=1.729, \mathrm{p}=0.22)$. The lowest observed flowering plant species richness in a plot

242 (23 spp.), was recorded at EL2 and the highest (82 spp.) at VG1. Overall, mean ( \pm 1SE) number

243 of observed species in a plot was $42.25( \pm 4.25)$. Estimated species richness (ICE) in a plot

244 ranged from $25 \mathrm{spp}$. (EL2) to $93 \mathrm{spp}$. (VG1), with a mean ICE of $61.13( \pm 5.37)$ in a plot. 
245 There was similar variation in recorded and estimated species richness of flower-visiting insects

246 ranging from a minimum of 19 observed species at VG1 and a maximum of 60 observed species

247 at HE2. A mean $( \pm 1 \mathrm{SE})$ of $36.94( \pm 2.67)$ species was observed across all plots. Estimated

248 richness (ICE) was highest at CO1 with 71 species, and lowest at VG1 with 36 species (Table 3).

249 Mean ICE across all plots was 38.28 ( \pm 2.30$)$. Analysis of variance analysis did not detect any

250 difference in estimated insect species richness between plots $(\mathrm{F}$-value $=1.182, \mathrm{p}=0.38)$. Species

251 diversity

252 There was no significant relationship between insect and plant diversity (t-value $=-1.10, \mathrm{p}=$

253 0.28).

254

255 Species turnover

256 The RELATE analysis between the plants and anthophiles was significant $(\rho=0.444, p<0.003)$,

257 suggesting significant concordance between the assemblages. However, turnover was weaker in

258 plants $(\rho=0.601, p<0.001)$ than in anthophiles $(\rho=0.883, p<0.001)$.

259 Power regressions showed that for the entire set of 120 pairwise comparisons, there was a

260 significant positive relationship in turnover for both plant $\left(R^{2}=0.443, p<0.001\right.$, Figure $\left.2 a\right)$, and

261 anthophile diversity $\left(\mathrm{R}^{2}=0.709, \mathrm{p}<0.001\right.$, Figure $\left.2 \mathrm{~b}\right)$ with increasing plot distance. The plot

262 pairs were spatially separated, but given the relatively small distances $(<80 \mathrm{~km})$ from a

263 biogeographical point of view, there were great differences between how the different plot pairs

264 shared plant species (Figure 2a) and anthophiles (Figure 2b) at the various distances, with

265 pairwise comparisons separating out into three distinct distance classes, $<10 \mathrm{~km}$ apart, 20-40 km

266 apart and 65-80 km apart (Figures $2 \mathrm{a}$ and $2 \mathrm{~b}$ ). Furthermore, there were significant positive

267 relationships in turnover within the different distance classes except for the $65-80 \mathrm{~km}$ group for

268 plants (Figure 2a) and 20-40 km group for anthophiles (Figure 2b), which were not significant.

269 Overall, these results point to great turnover of species even at relatively small geographical

270 distances.

271

272 Effect of plant species composition on insect species composition

273 Plant species composition did not have a significant effect on anthophile species composition (F-

274 value $=2.92, p=0.136$ ). The results of RDA revealed that eight plant species explained $60 \%$ of 
275 the variation in anthophile species composition, geographical distance explained 39\% and 1\%

276 remained unexplained.

277

278

Effect of vegetation structure on insect community composition

279 Of the nine variables tested, stepwise selection showed that plant species composition, flower

280 cover, plant species richness and average vegetation height were the four most influential

281 variables, collectively explaining $51 \%$ of the total variation in the anthophile assemblage data

282 (Figure 3). Variance partitioning suggested that flower cover was the most important variable,

283 accounting for $22.1 \%$ of variation followed by plant composition (10\%), mean vegetation height

$284(6.9 \%)$ and plant species richness (3.4\%). A further $8.7 \%$ of the variation could not be attributed

285 to any particular one of these variables.

286

287

\section{Discussion}

288

289

290

\section{Species turnover}

Dissimilarity between distance plot pairs increased similarly for both insects and plants, with increasing plot pair distance in the subgroups. This is consistent with other findings on other insect functional groups in the Cape Floristic Region (Procheş \& Cowling, 2006; Wright \& Samways, 1998; Procheş et al., 2009). There was also high turnover of insect species across the landscape, and to a lesser extent the flora. Even nearby sites showed a high degree of distinctness, with no site sharing more than $29 \%$ of plant species and $35 \%$ of anthophile species, suggesting high spatial heterogeneity for both groups.

Species turnover was apparent across increasing distance with distinct differences observable from the local $(<10 \mathrm{~km})$ to the regional $(>60 \mathrm{~km})$ distances. Species turnover, even at a local distance, was high, and was higher in insects than plants. Interestingly, in plants, turnover decreased with greater distance between plot pairs, from local to regional. In contrast, with insects there was high turnover at both the local and regional distances, with a tendency to increase across distance groups. This pattern is most likely a result due to the distances between the distance groups. Firstly, the distance ranges between groups A (Cordoba, Vergelegen,

304 Helderberg) and C (Elandskloofberge, $66-73 \mathrm{~km}$ ) and groups B (Klipfontein and Groenlandberg

305 Cconservancy) and C (68- $77 \mathrm{~km})$ overlap. Secondly, the study sites were intentionally placed in 
306 sites with near-natural, transformed, remnant or disturbed vegetation. Thus in all distance groups

307 all vegetation statuses are represented.

308 Caterino (2007) found high levels of spatial variation in beetles across three ecoregions in

309 the California Floristic Province, and concluded that this may be a general characteristic of insect

310 assemblages in Mediterranean-type ecosystems. In Caterino's (2007) study, plant assemblages

311 and their associated anthophiles, both the local and regional distances had congruent patterns of

312 turnover between sites, but incongruent patterns of species richness. In that study too, there was

313 high spatial variation of anthophiles, and there were no clear patterns in species richness.

314 However, in contrast to Caterino's (2007) study, our results showed that while the overall pattern

315 of turnover was similar in plants and anthophiles, the patterns within distance classes varied,

316 with the patterns between plants and insects diverging with greater plot-pair distance classes.

317

318 Congruence between plant and insect assemblages

319 We found a strong (44\%) positive relationship between plant and anthophile turnover, as has

320 been found in Europe (Ebeling et al. 2008; Papanikolaou et al. 2017), suggesting that such a

321 relationship is geographically widespread. However, in terms of concordance, this means that the

322 areas with similar plant assemblages do not necessarily share similar insect assemblages. This

323 decoupling between the two groups means that plant diversity alone is not a reliable surrogate for

324 insect diversity, at least at the various distance scales examined here. Indeed, plant-insect

325 relationships are highly variable across biomes, scales and insect guilds, suggesting that in each

326 case, different factors may drive insect diversity (Procheş et al. 2009).

327

328 Factors affecting diversity of flower-visiting insects

329 Given the diverse range of taxa encompassed by the entire assemblage of anthophiles, it is

330 difficult to generalise about which factors are most important. The four most influential variables

331 here are likely to represent some of the resource needs of this assemblage, but do not account for

332 all of the observed variation. The fact that flower cover (a measure of the relative abundance of

333 resources for anthophiles) was far more important than plant richness and diversity suggests that

334 resource availability is an important determinant of flower-visitor diversity and abundance,

335 particularly at the local scale (Hegland \& Boeke, 2006). 

highly specialised pollination systems (Johnson \& Steiner, 2003, Pauw \& Stanway, 2015), so it composition. However, functional relationships between plants and anthophiles are characterised by a high degree of asymmetry (Trøjelsgaard \& Olesen, 2013). Anthophiles visiting a specialised plant can be taxonomically diverse, although even specialised pollinators may visit a range of non-specialised plants, they often look for similar amino-acid based resources in plants which confer physiological advantages upon them (Nepi, 2014). The degree of ecological specialisation observed at any one time can be affected by various spatial and temporal factors (Petanidou \& Potts, 2006; Fontúrbel, 2015), meaning that plant and pollinator species composition may not necessarily be tightly coupled. Although resources for anthophiles are affected by the richness and composition of the local flora, the abundance and quality of suitable resources is not always directly related to plant species richness alone.

\section{Conclusions}

To summarize, we compared species richness and turnover relationships between flowering plants and flower-visiting insects across geographic distance $(0.5-80 \mathrm{~km})$ in a biodiversity hotspot, the Cape Floristic Region, South Africa. While we found there to be significant concordance between plants and anthophile assemblages $(\rho=0.444, p<0.003)$, turnover was weaker in plants $(\rho=0.601, p<0.001)$ than in anthophiles $(\rho=0.883, p<0.001)$, and decreased with greater geographical distance between plot pairs. In contrast, insect turnover remained high with increasing geographical distance between plot pairs. Furthermore, flowering plant species composition did not have a significant effect on anthophile species composition (Fvalue $=2.92, \mathrm{p}=0.136$ ). The discordance between the results here and those of other studies such as Procheş et al. (2009), as well as the inconsistencies noted by those authors, indicate that the factors affecting distributions differ between various taxonomic groups and can confound attempts to draw general conclusions about the relationships between plant and insect speciesrichness. These findings suggest that while patterns of plant diversity and distribution shape flower-visiting insect assemblages, they are not reliable surrogates. densely sampled than flowering-plants to ascertain their full spatial diversity. Secondly, 
367 conserving plants in the various parts of this species-rich biodiversity hotspot does not guarantee

368 that all the pollinating insects will also be conserved, with the insects, in effect, being more

369 fragmented than the plants. On the other hand, to conserve all the insects in the area, more land

370 must be set aside for them, while on the other, certain specialist plants may not have their

371 pollinators present. Overall, specialist plant-insect mutualisms are more vulnerable than

372 generalist ones. Conservation activities that improve functional connectivity across the overall

373 landscape will help maintain these plant-insect mutualisms. This may include establishing

374 conservancies where set-aside land is an intrinsic part of the agricultural landscape.

375 Intercropping using a range of vegetation is extensively employed but a move to vegetate

376 towards indigenous fynbos could be instigated to a greater extent. These approaches are feasible

377 at least in vineyards (the dominant agricultural type in this area) under the Biodiversity and Wine

378 Initiative (http://wine.co.za) with which many vineyards have partnered.

379

380

\section{Acknowledgements}

381 We thank C. Eardley, S. van Noort and H. Geertsema for taxonomic advice. We would also like

382 to thank the two anonymous reviewers who have taken the time to read and give critical input on 383 the manuscript. 


\section{References}

386 Baselga, A., Orme, C.D.L. 2012. betapart: an R package for the study of beta diversity. Methods

387 in Ecology and Evolution, 3, 808-812

388 Baselga, A. (2010) Partitioning the turnover and nestedness components of beta diversity. Global 389 Ecology and Biogeography, 19, 134-143.

390 Borcard, D., Legendre, P., \& Drapeau, P. (1992) Partialling out the spatial component of 391 ecological variation. Ecology, 73, 1045-1055.

392 Brower, J.C., \& Kyle, K.M. (1988) Seriation of an original data matrix as applied to 393 palaeoecology. Lethaia, 21, 79-93.

394 Campbell, J.W. \& Hanula, J.L. (2007) Efficiency of Malaise traps and colored pan traps for 395 collecting flower-visiting insects from three forested ecosystems. Journal of Insect Conservation, 396 11, 399-408.

397 Caterino, M.S. (2007) Species richness and complementarity of beetle faunas in a mediterranean398 type biodiversity hotspot. Biodiversity and Conservation, 16, 3993-4007.

399 Chao, A., Hwang, W.H., Chen, Y.C., \& Kuo, C.Y. (2000) Estimating the number of shared 400 species in two communities. Statistica Sinica, 10, 227-246.

401 Clarke, K. R., Warwick, R. M., \& Brown, B. E. (1993) An index showing breakdown of 402 seriation, related to distirbance, in a coral-reef assemblage. Marine Ecology Progress Series, 403 102, 153-160.

404 Clarke, K.R. \& Warwick, R.M. (2001) Change in marine communities: an approach to 405 statistical analysis and interpretation, 2nd edn, PRIMER-E Ltd, Plymouth, UK.

406 Colwell, R. K. (2009) EstimateS: Statistical estimation of species richness and shared species 407 from samples., Version 8.0, University of Conneticut, Storrs, CT, USA.

408 Colwell, R.K., Chao, A., Gotelli, N.J., Lin, S.-Y., Mao, C.X., Chadzon, R.L. \& Longino, J.T. 409 (2012) Models and estimators linking individual-based and sample-based rarefaction, 410 extrapolation and comparison of assemblages. Journal of Plant Ecology, 5, 3-21. 
411 Cowling, R.M. \& Heijnis, C.E. (2001) The identification of Broad Habitat Units as biodiversity 412 entities for systematic conservation planning in the Cape Floristic Region. South African Journal 413 of Botany, 67, 15-38.

414 Cowling, R.M., Pressey, R.L., Rouget, M., \& Lombard, A.T. (2003) A conservation plan for a 415 global biodiversity hotspot - the Cape Floristic Region, South Africa. Biological Conservation, 416 112, 191-216.

417 Dauber, J., Hirsch, M., Simmering, D., Waldhardt, R., Otte, A., \& Wolters, V. (2003) Landscape 418 structure as an indicator of biodiversity: matrix effects on species richness. Agriculture 419 Ecosystems and Environment, 98, 321-329.

420 Duelli, P. \& Obrist, M.K. (1998) In search of the best correlates for local organismal biodiversity 421 in cultivated areas. Biodiversity and Conservation, 7, 297-309.

422 Ebeling, A., Klein, A.M., Schumacher, J., Weisser, W.W. and Tscharntke, T. (2008) How does 423 plant richness affect pollinator richness and temporal stability of flower visits? Oikos, 117, 18084241815.

425 Favreau, J.M., Drew, C.A., Hess, G.R., Rubino, M.J., Koch, F.H. \& Eschelbach, K.A. (2006) 426 Recommendations for assessing the effectiveness of surrogate species approaches. Biodiversity 427 and Conservation, 15, 3949-3969.

428 Forest, F., Grenyer, R., Rouget, M., Davies, T.J., Cowling, R.M., Faith, D.P., Balmford, A., 429 Manning, J.C., Procheş, S., van der Bank, M., Reeves, G., Hedderson, T.A.J., \& Savolainen, V. 430 (2007) Preserving the evolutionary potential of floras in biodiversity hotspots. Nature, 445, 757431760.

432 Fontúrbel, F.E., Jordano, P., \& Medel, R. (2015) Scale-dependent responses of pollination and 433 seed dispersal mutualisms in a habitat transformation scenario. Journal of Ecology, 103, 1334$434 \quad 1343$.

435 Giliomee, J.H. (2003) Insect diversity in the Cape Floristic Region. African Journal of Ecology, 436 41, 237-244. 
437 Gill, R.J., Baldock, K.C., Brown, M.J., Cresswell, J.E., Dicks, L.V., Fountain, M.T., Garratt, 438 M.P., Gough, L.A., Heard, M.S., Holland, J.M., \& Ollerton, J. (2016) Protecting an ecosystem 439 service: approaches to understanding and mitigating threats to wild insect pollinators. Advances 440 in Ecological Research, 54, 135-205.

441 Goldblatt, P. \& Manning, J.C. (2002) Plant diversity of the Cape region of southern Africa. 442 Annals of the Missouri Botanical Garden, 89, 289-302.

443 Goulson, D., Nicholls, E., Botías, C., \& Rotheray, E.L. (2015) Bee declines driven by combined 444 stress from parasites, pesticides, and lack of flowers. Science, 347, 1255957.

445 Grantham, H.S., Pressey, R.L., Wells, J.A. \& Beattie, A.J. (2010) Effectiveness of biodiversity 446 surrogates for conservation planning: Different measures of effectiveness generate a 447 kaleidoscope of variation. PloS One, 5, e11430, 1-12.

448 Hegland, S.J. \& Boeke, L. (2006) Relationships between the density and diversity of floral 449 resources and flower visitor activity in a temperate grassland community. Ecological 450 Entomology, 31, 532-538.

451 Hickling, R., Roy, D.B., Hill, J.K., Fox, R. and Thomas, C.D. (2006) The distributions of a wide 452 range oftaxonomic groups are expanding polewards. Global Change Biology, 12, 450-455.

453 Hood, G.(2008) PopTools, Version 3.06, CSIRO, Canberra, Australia.

454 Hortal, J., Borges, P.A.V., \& Gaspar, C. (2006) Evaluating the performance of species richness 455 estimators: sensitivity to sample grain size. Journal of Animal Ecology, 75, 274-287.

456 Johnson, S.D. \& Steiner, K.E. (2003) Specialized pollination systems in southern Africa. South 457 African Journal of Science, 99, 345-348.

458 Joppa, L.N., O'Connor, B., Visconti, P., Smith, C., Geldmann, J., Hofmann, M., Watson, M., 459 Butchart, S.H.M., Virah-Sawmy, M., Halpern, B.S., Ahmed, S.E., Balmford, A., Sutherland, 460 W.J., Harfoot, M., Hilton-Taylor, C., Foden, W., Di Minin, E., Pagad, S., Genovesi, P., Hutton, 461 J., \& Burgess, N.D. (2016) Filling in the biodiversity threat gaps. Science, 352, 416-418. 
462 Kemp, J.E. \& Ellis, A.G. (2017) Significant local-scale plant-insect species richness relationship 463 independent of abiotic effects in the temperate Cape Floristic Region biodiversity hotspot. PLoS 464 One, 12, e0168033. doi:10.1371/ journal.pone.0168033Kemp, J. E., Linder, H. P. \& Ellis, A. G. 465 (2017) Beta diversity of hebivorous insects is coupled to high species and phylogenetic turnover 466 of plant communities across short spatial scales in the Cape Floristic Region. Journal of 467 Biogeography 44, 1813-1823.

468 Kirkman, L.K.,, Smith, L.L., Quintana-Ascencio, P.F., Kaeser, M.J., Golladay, S.W. \& Farmer, 469 A.L. (2012) Is species richness congruent among taxa? Surrogacy, complementarity, and 470 environmental correlates among three disparate taxa in geographically isolated wetlands. 471 Ecological Indicators, 18,131-139.Kremen, C. (1992) Assessing the indicator properties of 472 species assemblages for natural areas monitoring. Ecological Applications, 2, 203-217.

473 Lamoreux, J.F., Morrison, J.C., Ricketts, T.H., Olson, D.M., Dinerstein, E., McKnight, M.W. \& 474 Shugart, H.H. (2006) Global tests of biodiversity concordance and the importance of endemism. 475 Nature, 440,212-214.Legendre, P. (2000) Comparison of permutation methods for the partial 476 correlation and partial Mantel tests. Journal of Statistical Computation and Simulation, 67, 37$477 \quad 73$.

478 Legendre, P., Fortin, M.-J. \& Borcard, D. (2015) Should the Mantel test be used in spatial 479 analysis? Methods in Ecology and Evolution, 6, 1239-1247.

480 Lepš, J. \& Šmilauer, P. (2003) Multivariate analysis of ecological data using CANOCO, 481 Cambridge University Press, Cambridge.

482 Longino, J.T., Coddington, J., \& Colwell, R.K. (2002) The ant fauna of a tropical rain forest: 483 Estimating species richness three different ways. Ecology, 83, 689-702.

484 Lovell, S., Hamer, M., Slotow, R. \& Herbert, D. (2007) Assessment of congruency across 485 invertebrate taxa and taxonomic levels to identify potential surrogates. Biological Conservation, 486 139, 113-125. 
487 McKnight, M.W., White, P.S., McDonald, R.I., Lamoreux, J.F., Sechrest, W., Ridgeley, R.S. \& 488 Stuart, S.N. (2007) Putting beta diversity on the map: broad-scale congruence and coincidence in 489 the extremes. PLoS Biology, 5, e272. https://doi.org/10.1371/journal.pbio.0050272

490 Nepi, M. (2014) Beyond nectar sweetness: the hidden ecological role of non-protein amino acids 491 in nectar. Journal of Ecology, 102, 108-115.

492 Novotny, V., Drozd, P., Miller, S.E., Kulfan, M., Janda, M., Basset, Y., \& Weiblen, G.D. (2006)

493 Why are there so many species of herbivorous insects in tropical rainforests? Science, 313, 1115 4941118.

495 O'Hara, R.B. (2005) Species richness estimators: how many species can dance on the head of a 496 pin? Journal of Animal Ecology, 74, 375-386.

497 Oliver, I. \& Beattie, A.J. (1996) Invertebrate morphospecies as surrogates for species: A case 498 study. Conservation Biology, 10, 99-109.

499 Oksanen, J., Blanchet, F. G., Friendly, M., Kindt, R., Legendre, P., McGlinn, D., Wagner, H. 500 (2018). Vegan: community ecology package. Version 2.4-6. Retrieved from https://cran.r501 project.org/web/packages/vegan/index.html

502 Osborn, F., Goitia, W., Cabrera, M., \& Jaffe, K. (1999) Ants, plants and butterflies as diversity 503 indicators: Comparisons between strata at six forest sites in Venezuela. Studies on Neotropical 504 Fauna and Environment, 34, 59-64.

505 Papanikolaou, A.D., Kühn, I., Frenzel, M., Kuhlmann, M., Poschlod, P., Potts, S.G., Roberts, 506 S.P.M. and Schweiger, O. (2017) Wild bee and floral diversity co-vary in response to the direct 507 and indirect impacts of land use. Ecosphere, 8(11), e02008.

508 Pauw, A. (2013) Can pollination niches facilitate plant coexistence? Trends in Ecology \& 509 Evolution, 28, 30-37.

510 Pauw, A., \& Stanway, R. (2015) Unrivalled specialization in a pollination network from South 511 Africa reveals that specialization increases with latitude only in the Southern Hemisphere.

512 Journal of Biogeography, 42, 652-661. 
513 Petanidou, T. \& Potts, S.G. (2006) Mutual use of resources in Mediterranean plant-pollinator

514 communities: How specialized are pollination webs?, Plant-pollinator interactions: from

515 specialization to generalization (ed. by N.M.Waser \& J.Ollerton), p. 220-244. University of

516 Chicago Press, Chicago, USA.

517 Pharo, E.J., Beattie, A.J. \& Binns, D. (1999) Vascular plant diversity as a surrogate for

518 bryophyte and lichen diversity. Conservation Biology, 13,282-292.

519 Picker, M.D. \& Midgley, J.J. (1996) Pollination by monkey beetles (Coleoptera: Scarabaeidae:

520 Hopliini): Flower and colour preferences. African Entomology, 4, 7-14.

521 Pimm, S.L., Jenkins, C.N., Abell, R., Brooks, T.M., Gittleman, J.L., Joppa, L.N., Raven, P.H.,

522 Roberts, C.M. \& Sexton, J.O. (2014) The biodiversity of species and their rates of extinction,

523 distribution, and protection. Science, 344, 987-997.

524 Ponel, P., Orgeas, J., Samways, M.J., Andrieu-Ponel, V., De Beaulieu, J.L., Reille, M., Roche, P.

$525 \&$ Tatoni, T. (2003) 110000 years of Quaternary beetle diversity change. Biodiversity and

526 Conservation, 12, 2077-2089.

527 Prendergast, J.R. (1997) Species richness covariance in higher taxa: empirical tests of the

528 biodiversity indicator concept. Ecography, 20, 210-216.

529 Pressey, R.L., Cowling, R.M., \& Rouget, M. (2003) Formulating conservation targets for

530 biodiversity pattern and process in the Cape Floristic Region, South Africa. Biological

531 Conservation, 112, 99-127.

532 Primer-E Ltd(2002) PRIMER 5, Version 5.2.9, Primer-E, Plymouth, UK.

533 Procheş, S. \& Cowling, R.M. (2006) Insect diversity in Cape fynbos and neighbouring South

534 African vegetation. Global Ecology and Biogeography, 15, 445-451.

535 Procheş, S., Forest, F., Veldtman, R., Chown, S.L., Cowling, R.M., Johnson,S.D., Richardson,

536 D.M., \& Savolainen, V. (2009) Dissecting the plant-insect diversity relationship in the Cape.

537 Molecular Phylogenetics and Evolution, 51, 94-99. 
538 Ricketts, T.H., Daily, G.C., Ehrlich, P.R. (2002) Does butterfly diversity predict moth diversity?

539 Testing a popular indicator taxon at local scales. Biological Conservation, 103, 361-270.

540 Rodrigues, A.S.L. \& Brooks, T.M. (2007) Shortcuts for biodiversity conservation planning: The

541 effectiveness of surrogates. Annual Review of Ecology Evolution and Systematics, 38, 713-737.

542 Rouget, M., Richardson, D.M., \& Cowling, R.M. (2003) The current configuration of protected 543 areas in the Cape Floristic Region, South Africa - reservation bias and representation of

544 biodiversity patterns and processes. Biological Conservation, 112, 129-145.

545 Saunders, M.E. \& Luck, G.W. (2013) Pan trap catches of pollinator insects vary with habitat.

546 Australian Journal of Entomology, 52, 106-113.

547 Socolar, J.B., Gilroy. J.J., Kunin, W.E., \& Edwards, D.P. (2016) How should beta-diversity

548 inform biodiversity conservation? Trends in Ecology and Evolution, 31, 67-80.

549 Sokal, R.R. \& Rohlf, F.J. (1995) Biometry: the principle and practice of statistics in biological

550 research, 3rd edn, W.H. Freeman, New York.

551 South African National Biodiversity Institute (2009) Plants of southern Africa (POSA): an online 552 checklist. Version 2.5. http://posa.sanbi.org. Accessed June 2009.

553 StatSoft Inc.(2007) STATISTICA (data analysis software system), Version 8.0, StatSoft Inc., 554 Tulsa.

555 Stork, N.E. \& Habel, J.C. (2014) Can biodiversity hotspots protect more than tropical forest 556 plants and vertebrates. Journal of Biogeography, 41,421-428.ter Braak, C. J. F and Šmilauer, 557 P.(2004) CANOCO, Version 4.53, Biometris - Plant Research International, Wagenigen.

558 Trøjelsgaard, K. and Olesen, J.M., 2013. Macroecology of pollination networks. Global Ecology 559 and Biogeography, 22, 149-162.

560 Tuell, J.K. \& Isaacs, R. (2009) Elevated pan traps to monitor bees in flowering crop canopies.

561 Entomologia Experimentalis et Applicata, 131, 93-98. 
562 Vanbergen, A.J., Baude, M., Biesmeijer, J.C., Britton, N.F., Brown, M.J., Brown, M., Bryden, J.,

563 Budge, G.E., Bull, J.C., Carvell, C., \& Challinor, A.J. (2013) Threats to an ecosystem service:

564 pressures on pollinators. Frontiers in Ecology and the Environment, 11, 251-259.

565 van Jaarsveld, A.S., Freitag, S., Chown, S.L., Muller, C., Koch, S., Hull, H., Bellamy, C.,

566 Kruger, M., Endrody-Younga, S., Mansell, M.W., \& Scholtz, C.H. (1998) Biodiversity

567 assessment and conservation strategies. Science, 279, 2106-2108.

568 Vrdoljak, S.M. \& Samways, M.J. (2012) Optimising coloured pan traps to survey flower-visiting 569 insects. Journal of Insect Conservation, 16, 345-354.

570 Vrdoljak, S.M. \& Samways, M.J. (2014) Agricultural mosaics maintain significan flower and 571 visiting insect biodiversity in a global hotspot. Biodiversity and Conservation, 23, 133-148.

572 Walther, B.A. \& Moore, J.L. (2005) The concepts of bias, precision and accuracy, and their use

573 in testing the performance of species richness estimators, with a literature review of estimator

574 performance. Ecography, 28, 815-829.

575 Wiens, J.A., Hayward, G.D., Holthausen, R.S. \& Wisdom, M.J. (2008) Using surrogate species 576 and groups for conservation planning and management. BioScience, 58, 241-252.

577 Wolters, V., Bengtsson, J., \& Zaitsev, A.S. (2006) Relationship among the species richness of 578 different taxa. Ecology, 87, 1886-1895.

579 Wright, M.G. \& Samways, M.J. (1998) Insect species richness tracking plant species richness in 580 a diverse flora: gall-insects in the Cape Floristic Region, South Africa. Oecologia, 115, 427-433.

581 Wright, M.G. \& Samways, M.J. (2000) Biogeography and species richness of endophagous 582 insects associated with Proteaceae in South Africa. African Journal of Ecology, 38, 16-22. 583 


\section{Supporting Information}

589 Additional Supporting Information may be found in the online version of this article:

590 Appendix S1 Distance table for all plots used in species turnover study.

591 Appendix S2 Insect and plant species identified from the study.

592 Appendix S3 Pan and plot assemblage similarity.

593

594 
595 Table 1 Descriptions and locations of study sites and plots used to assess complementarity of 596 anthophile and plant species assemblages in the lowlands of the Cape Floristic Region

597

598 Table 2 Vegetation structure and composition variables calculated from $50 \mathrm{~m}$ line transect data 599 for sixteen plots in the lowlands of the Cape Floristic Region.

600

601 Table 3. Non-parametric species-richness estimates using an abundance based species richness 602 estimator, the Incidence Coverage Estimator (ICE) for a) flowering plants and b) flower-visiting 603 insects from 16 plots in the lowlands Cape Floristic Region. Obs = observed number of species. 604 
605 Fig. 1. Study area map, experimental design and study sites. Map of study sites within the Cape 606 Floristic Region (A). Black circles = Cordoba $(\mathrm{CO} 1-2)$, squares $=$ Elandskloofberge $($ EL1-4),

607 triangles $=$ Helderberg Municipal Nature Reserve (HE1-3), star = Klipfontein (KL1), crosses = 608 Groenlandberg Conservancy (GB1-3), diamonds = Vergelegen (VG1-2). Experimental design at 609 each plot (B). For each plot, three arrays of randomly arranged coloured pan traps (blue, red, 610 orange, violet, white and yellow) were placed in a configuration as shown. Elandskloofberge site 611 (EL3) with natural vegetation and located within reserve (C). Elandskloofberge remnant site 612 surrounded by canola (as seen in background) and wheat fields (D). Photography by Sven 613 Vrdoljak.

614

615 Fig. 2. Species turnover of plants (A) and insects (B) as represented by Sorensen pair-wise 616 dissimilarity between plot pairs at four spatial scales in the lowlands of the Cape Floristic 617 Region. Each point represents a pair of sites (120 possible combinations). Dashed line indicates 618 best fit of a power curve for all points, while solid lines are best fit for each subgroup of pairs in 619 three distance classes: 0-10 km, 20-40 km, 60-80 km. Number of pairs per distance sub-group 620 are: Blue: $\mathrm{N}=40$; Yellow: $\mathrm{N}=32$; and Grey: $\mathrm{N}=48$. All regression lines are shown ( $\mathrm{ns}=$ not 621 significant, $* * \mathrm{p} \leq 0.001, * * * \mathrm{p} \leq 0.000)$.

622

623 Fig. 3. Biplot from the RDA of anthophile assemblages at sixteen sites in the lowlands of the 624 Cape Floristic Region. Sizes of the circles indicate relative species richness for each site. Arrows 625 indicate the best subset of four vegetation structure variables chosen by forward selection during 626 ordination. For each variable, the relative contribution to the total variation of $51.1 \%$ explained 627 by the canonical axes is given in parentheses.

628 


\section{Table $\mathbf{1}$ (on next page)}

Descriptions and locations of study sites and plots used to assess complementarity of anthophile and plant species assemblages in the lowlands of the Cape Floristic Region 


\begin{tabular}{|c|c|c|c|}
\hline Site/plot & Description & Location & Status \\
\hline \multicolumn{4}{|c|}{$\begin{array}{l}\text { Elandskloofberge - Elandsberg Private Nature Reserve (EL), 4,000 ha in extent, remnants on } \\
\text { neighbouring Bartholomeusklip farm. All sites within } 3 \mathrm{~km} \text { radius. }\end{array}$} \\
\hline EL1 & $\begin{array}{l}\text { Remnant adjacent to reserve. } \\
\text { Surrounded by wheatfields }\end{array}$ & $33.4482^{\circ} \mathrm{S}, 19.0272^{\circ} \mathrm{E}$ & Remnant \\
\hline EL2 & Old field on border of reserve & $33.4438^{\circ} \mathrm{S}, 19.0291^{\circ} \mathrm{E}$ & Transformed \\
\hline EL3 & $\begin{array}{l}\text { Natural vegetation within reserve. } \\
\text { BIOTA observatory site }\end{array}$ & $33.448^{\circ} \mathrm{S}, 19.0474^{\circ} \mathrm{E}$ & Reserve \\
\hline EL4 & $\begin{array}{l}\text { Remnant surrounded by canola and } \\
\text { wheatfields. Some disturbance by } \\
\text { feral pigs }\end{array}$ & $33.4536^{\circ} \mathrm{S}, 19.0162^{\circ} \mathrm{E}$ & Remnant \\
\hline \multicolumn{4}{|c|}{$\begin{array}{l}\text { Helderberg Region - Helderberg Municipal Nature Reserve (HE), } 396 \text { ha in extent, and remnants } \\
\text { on nearby wine estates Cordoba (CO) and Vergelegen (VG). All sites within a } 9 \mathrm{~km} \text { radius. }\end{array}$} \\
\hline HE1 & $\begin{array}{l}\text { Firebreak on margin of reserve, } \\
\text { adjacent to golf estate }\end{array}$ & $34.059^{\circ} \mathrm{S}, 18.8772^{\circ} \mathrm{E}$ & Disturbed \\
\hline HE2 & Natural vegetation in within reserve & $34.0618^{\circ} \mathrm{S}, 18.8749^{\circ} \mathrm{E}$ & Reserve \\
\hline HE3 & $\begin{array}{l}\text { Natural vegetation on former } \\
\text { plantation area }\end{array}$ & $34.0573^{\circ} \mathrm{S}, 18.8676^{\circ} \mathrm{E}$ & Reserve \\
\hline $\mathrm{CO} 1$ & $\begin{array}{l}\text { Former vineyard, replanted with } \\
\text { natural vegetation }\end{array}$ & $34.0334^{\circ} \mathrm{S}, 18.8488^{\circ} \mathrm{E}$ & Transformed \\
\hline $\mathrm{CO} 2$ & $\begin{array}{l}\text { Fragment between current } \\
\text { vineyards, moribund, with invasive } \\
\text { grasses }\end{array}$ & $34.0313^{\circ} \mathrm{S}, 18.856^{\circ} \mathrm{E}$ & Remnant \\
\hline VG1 & $\begin{array}{l}60 \text { ha patch of largely intact } \\
\text { renosterveld, adjacent to vineyards. }\end{array}$ & $34.0948^{\circ} \mathrm{S}, 18.8974^{\circ} \mathrm{E}$ & Remnant \\
\hline VG2 & $\begin{array}{l}\text { Area cleared of IAPs adjacent to } \\
\text { vineyard. Recovering vegetation } \\
\text { with invasive Echium } \\
\text { plantagenium. }\end{array}$ & $34.0886^{\circ} \mathrm{S}, 18.8935^{\circ} \mathrm{E}$ & Transformed \\
\hline VG3 & $\begin{array}{l}\text { Old firebreak, } 40 \text { m wide with } \\
\text { natural vegetation between dense } \\
\text { stands of Acacia mearnsii. }\end{array}$ & $34.0763^{\circ} \mathrm{S}, 18.923^{\circ} \mathrm{E}$ & Disturbed \\
\hline \multicolumn{4}{|c|}{$\begin{array}{l}\text { Groenlandberg Conservancy - reserve site in section of the Hottentots Holland Provincial Nature } \\
\text { Reserve at Klipfontein (KL), } 42,000 \text { ha in extent, and remnants on Diepklowe Private Nature } \\
\text { Reserve and olive farm (GB). All sites within a 10km radius. }\end{array}$} \\
\hline KL1 & $\begin{array}{l}\text { Large block of relatively } \\
\text { undisturbed natural vegetation } \\
\text { situated near Theewaterskloof dam }\end{array}$ & $34.0546^{\circ} \mathrm{S}, 19.169^{\circ} \mathrm{E}$ & Reserve \\
\hline GB1 & $\begin{array}{l}\text { Relatively intact remnant adjacent } \\
\text { to fallow wheat field. }\end{array}$ & $34.1017^{\circ} \mathrm{S}, 19.2496^{\circ} \mathrm{E}$ & Remnant \\
\hline GB2 & $\begin{array}{l}\text { Firebreak in area of moribund, } \\
\text { Elytropappus rhinocerotis }\end{array}$ & $34.1035^{\circ} \mathrm{S}, 19.2462^{\circ} \mathrm{E}$ & Disturbed \\
\hline GB3 & $\begin{array}{l}\text { Disturbed, but recovering area of } \\
\text { natural vegetation on ridge above } \\
\text { farm. }\end{array}$ & $34.1099^{\circ} \mathrm{S}, 19.2448^{\circ} \mathrm{E}$ & Transformed \\
\hline
\end{tabular}




\section{Table 2 (on next page)}

Vegetation structure and composition variables calculated from $50 \mathrm{~m}$ line transect data for sixteen plots in the lowlands of the Cape Floristic Region. 


\begin{tabular}{|c|c|}
\hline Variable & Description \\
\hline Plant cover & $\begin{array}{l}\text { Total length }(\mathrm{m}) \text { per transect covered by vegetation (excludes open ground, with } \\
\text { litter, woody debris and sparse seedling cover). }\end{array}$ \\
\hline Vegetation height & Mean height $(\mathrm{cm})$ of vegetation per transect. \\
\hline Flower cover & Total length $(\mathrm{m})$ per transect covered by plants in flower at time of survey. \\
\hline Open ground & $\begin{array}{l}\text { Total length }(\mathrm{m}) \text { per transect not covered by plant canopy (includes open ground } \\
\text { with litter, woody debris and sparse seedling cover) }\end{array}$ \\
\hline Plant composition & $\begin{array}{l}\text { Index of similarity between all plots based on plant species composition using } \\
\text { first axis scores from a detrended correspondence analysis }\end{array}$ \\
\hline Plant richness & $\begin{array}{l}\text { Estimated plant species richness per plot from Incidence Coverage Estimator, } \\
\text { ICE (Chao et al., 2000) }\end{array}$ \\
\hline Flower richness & $\begin{array}{l}\text { Estimated species richness of flowering plants per plot from Incidence } \\
\text { Coverage Estimator, ICE (Chao et al., 2000) }\end{array}$ \\
\hline Annuals & $\begin{array}{l}\text { Total length }(\mathrm{m}) \text { per transect covered by annual species per plot. Plant species } \\
\text { classified according to POSA (South African National Biodiversity Institute } \\
\text { 2009) }\end{array}$ \\
\hline Perennials & $\begin{array}{l}\text { Total length }(\mathrm{m}) \text { per transect covered by perennial species per plot. Species } \\
\text { classified according to information in POSA. }\end{array}$ \\
\hline
\end{tabular}




\section{Table 3(on next page)}

Non-parametric species-richness estimates using an abundance based species richness estimator, the Incidence Coverage Estimator (ICE) for a) flowering plants and b) flowervisiting insects from 16 plots in the lowlands Cape Floristic Region.

Obs $=$ observed number of species. 


\begin{tabular}{|c|c|c|c|}
\hline \multicolumn{4}{|c|}{ a) Flowering plants } \\
\hline & $\mathrm{N}^{\dagger}$ & Obs. & ICE ( \pm S.D.) \\
\hline $\mathrm{CO} 1$ & 3 & 29 & $36.31( \pm 12.94)$ \\
\hline $\mathrm{CO} 2$ & 3 & 20 & $32.53( \pm 12.52)$ \\
\hline EL1 & 3 & 57 & $87.15( \pm 29.23)$ \\
\hline EL2 & 3 & 23 & $25.11( \pm 4.87)$ \\
\hline EL3 & 3 & 34 & $73.19( \pm 27.31)$ \\
\hline EL4 & 3 & 39 & $75.53( \pm 18.98)$ \\
\hline HE1 & 3 & 56 & $72.69( \pm 17.28)$ \\
\hline HE2 & 3 & 43 & $63.82( \pm 18.37)$ \\
\hline HE3 & 3 & 42 & $52.18( \pm 8.64)$ \\
\hline KL1 & 3 & 54 & $89.67( \pm 39.63)$ \\
\hline GB1 & 3 & 45 & $53.9( \pm 14.85)$ \\
\hline GB2 & 3 & 62 & $78.05( \pm 33.52)$ \\
\hline GB3 & 3 & 18 & $38.3( \pm 15.17)$ \\
\hline VG1 & 3 & 82 & $92.64( \pm 18.56)$ \\
\hline VG2 & 3 & 40 & $62.63( \pm 22.37)$ \\
\hline VG3 & 3 & 32 & $44.34( \pm 13.03)$ \\
\hline
\end{tabular}

b) Anthophiles

\begin{tabular}{llll}
\hline & $\mathrm{N}^{\ddagger}$ & Obs. & ICE $( \pm$ S.D. $)$ \\
\hline CO1 & 3 & 57 & $70.52( \pm 15.52)$ \\
$\mathrm{CO} 2$ & 3 & 31 & $55.55( \pm 17.11)$ \\
$\mathrm{EL} 1$ & 3 & 41 & $51.08( \pm 13.22)$ \\
$\mathrm{EL} 2$ & 3 & 38 & $47.54( \pm 10.58)$ \\
$\mathrm{EL} 3$ & 3 & 35 & $45.04( \pm 8.23)$ \\
$\mathrm{EL} 4$ & 3 & 35 & $37.84( \pm 7.75)$ \\
$\mathrm{HE} 1$ & 3 & 40 & $56.66( \pm 13.12)$ \\
$\mathrm{HE} 2$ & 3 & 60 & $64.5( \pm 13.24)$ \\
$\mathrm{HE} 3$ & 3 & 46 & $63.17( \pm 23.15)$ \\
$\mathrm{KL} 1$ & 3 & 33 & $45.3( \pm 13.28)$ \\
$\mathrm{GB} 1$ & 3 & 27 & $47.11( \pm 20.56)$ \\
$\mathrm{GB} 2$ & 3 & 26 & $39.41( \pm 15.93)$ \\
$\mathrm{GB} 3$ & 3 & 31 & $39.48( \pm 12.81)$ \\
VG1 & 3 & 19 & $36( \pm 16.03)$ \\
VG2 & 3 & 40 & $62.63( \pm 22.37)$ \\
VG3 & 3 & 32 & $44.34( \pm 13.03)$ \\
\hline
\end{tabular}




\section{Figure 1}

Study area map, experimental design and study sites.

Map of study sites within the Cape Floristic Region (A). Black circles = Cordoba (CO1-2), squares $=$ Elandskloofberge $($ EL1-4), triangles $=$ Helderberg Municipal Nature Reserve (HE13), star = Klipfontein (KL1), crosses = Groenlandberg Conservancy (GB1-3), diamonds = Vergelegen (VG1-2). Experimental design at each plot (B). For each plot, three arrays of randomly arranged coloured pan traps (blue, red, orange, violet, white and yellow) were placed in a configuration as shown. Elandskloofberge site (EL3) with natural vegetation and located within reserve (C). Elandskloofberge remnant site surrounded by canola (as seen in background) and wheat fields (D). Photography by Sven Vrdoljak. 


\section{A}

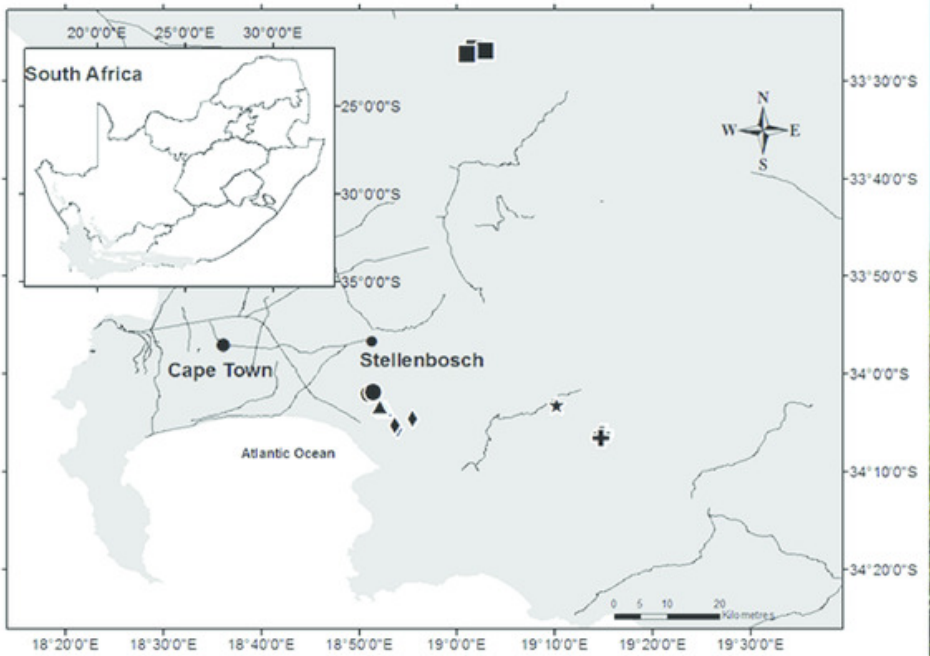

C

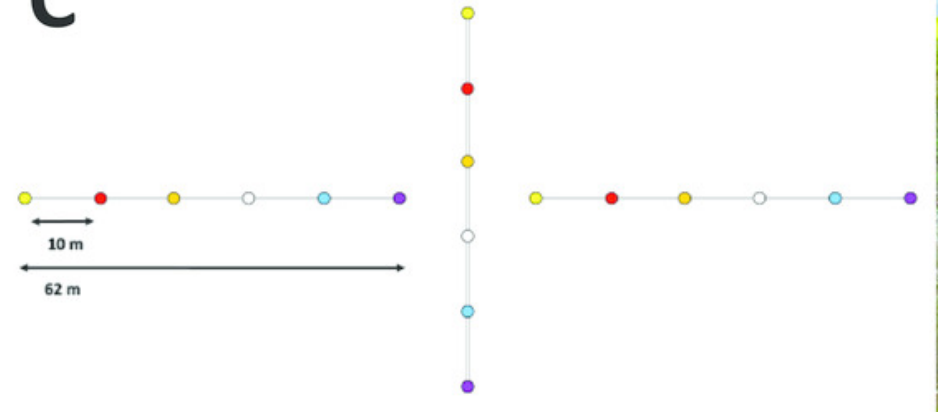

B

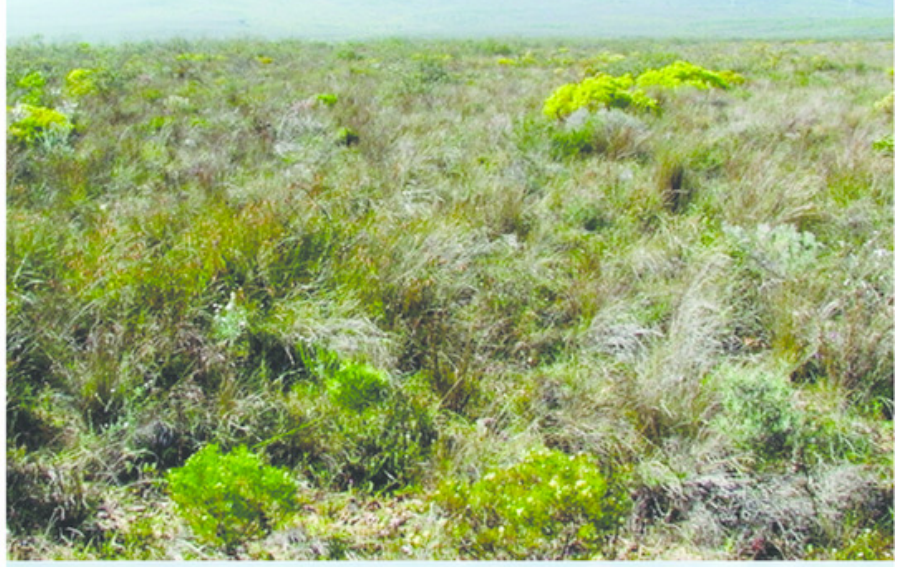

D

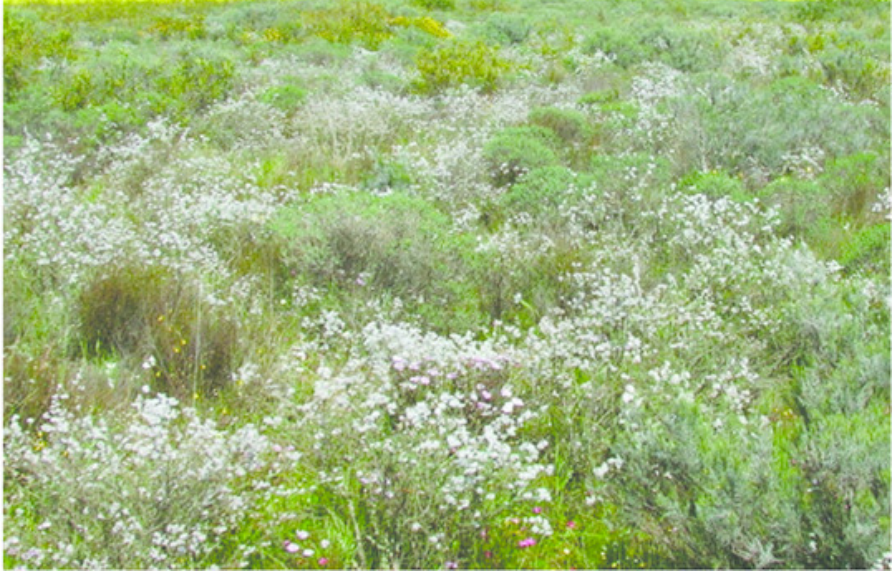




\section{Figure 2}

Species turnover of plants (A) and insects (B) as represented by Sorensen pair-wise dissimilarity between plot pairs at four spatial scales in the lowlands of the Cape Floristic Region.

Each point represents a pair of sites (120 possible combinations). Dashed line indicates best fit of a power curve for all points, while solid lines are best fit for each subgroup of pairs in three distance classes: 0-10 km, 20-40 km, 60-80 km. Number of pairs per distance subgroup are: Blue: $\mathrm{N}=40$; Yellow: $\mathrm{N}=32$; and Grey: $\mathrm{N}=48$. All regression lines are shown (ns $=$ not significant, $\left.{ }^{* *} p \leq 0.001,{ }^{* * *} p \leq 0.000\right)$. 

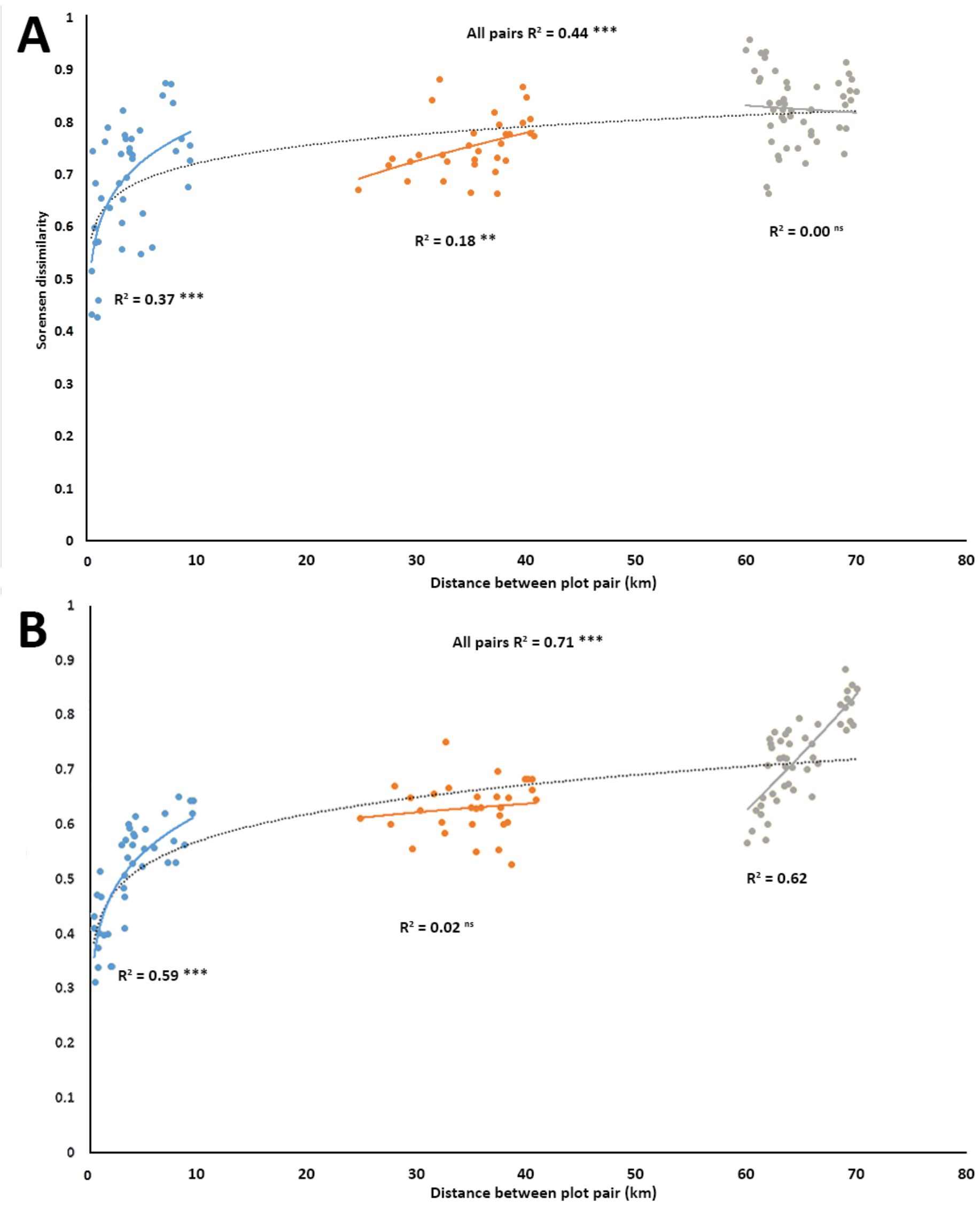


\section{Figure 3}

Biplot from the RDA of anthophile assemblages at sixteen sites in the lowlands of the Cape Floristic Region.

Sizes of the circles indicate relative species richness for each site. Arrows indicate the best subset of four vegetation structure variables chosen by forward selection during ordination. For each variable, the relative contribution to the total variation of $51.1 \%$ explained by the canonical axes is given in parentheses. 


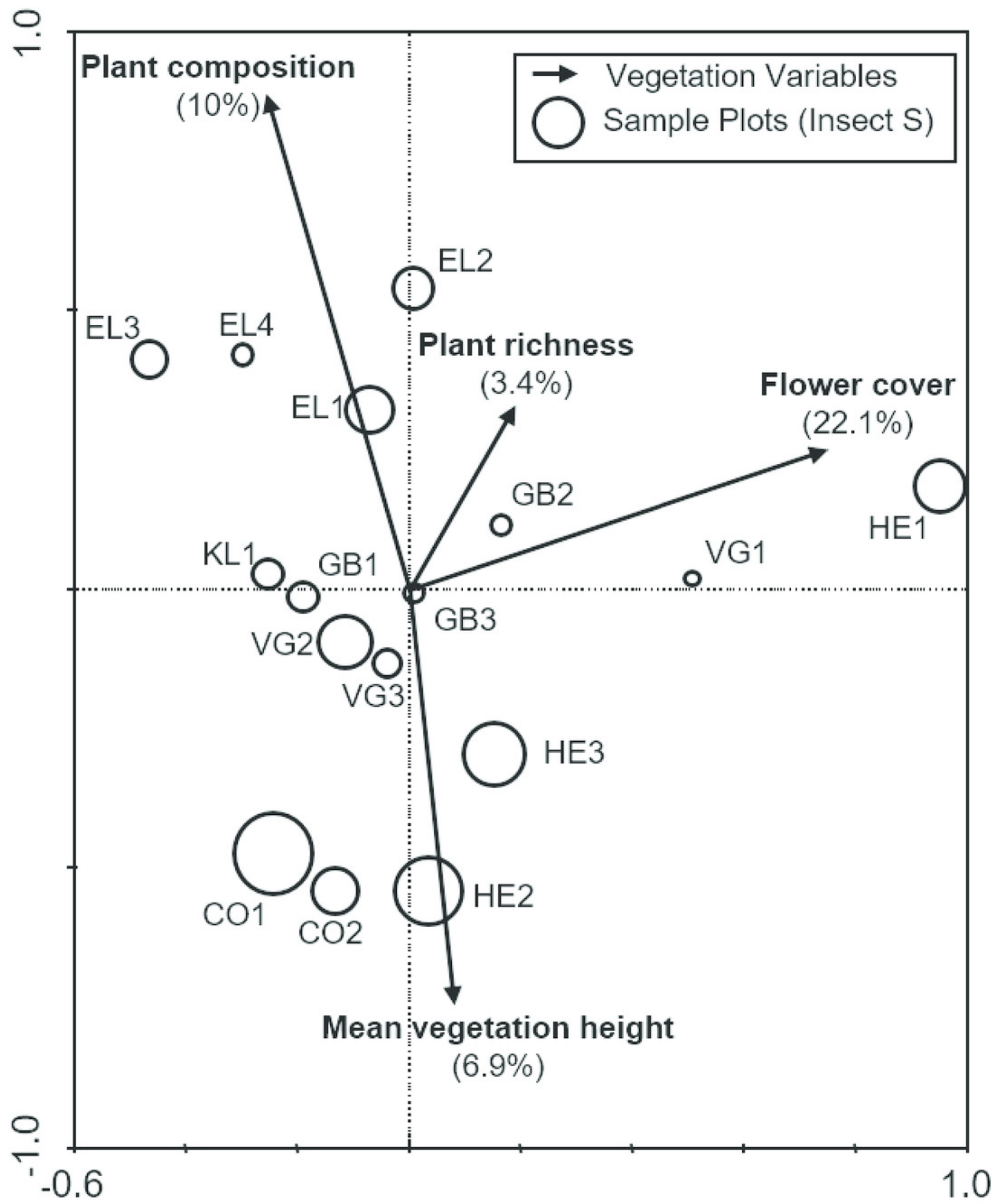

Sum of all canonical eigenvalues $=0.511$,

Monte Carlo permutation test for all axes, $\mathrm{F}=2.868, \mathrm{P}=0.006$ 